\title{
Comparative evaluation of maize inbred lines (zea mays I.) according to dus testing using morphological, physiological and molecular markers
}

\author{
Vinod Kumar Yadav*, Indra Sen Singh \\ Department of Genetics and Plant Breeding, G.B. Pant University of Agriculture and Technology, Pantangar, India; \\ *Corresponding Author: vinodbreeder@in.com
}

Received 22 June 2010; revised 3 August 2010; accepted 7 August 2010.

\begin{abstract}
A major challenge facing those involved in the testing of new plant varieties for Distinctness, Uniformity and Stability (DUS) is the need to compare them against all those of 'common knowledge'. A set of maize inbred lines was used to compare how morphological, physiological characterization and RAPD molecular marker described variety relationships. All the inbred lines were confirmed as morphologically and physiologically distinct. At morphological level the maximum genetic distance (10.8) and least genetic distance (1.6) were found. For physiological characters distance varied from 0.35 to 1.92 and results from dendrogram, which was made on the basis of dissimilarity matrix, were grouped into five major clusters. From RAPD, random primers provide polymorphic amplification products; the distance varying 0.42 to 0.65 and dendrogram showed that these lines formed close clusters due to the less variation in these lines at molecular level. In the present study, the molecular markers also exposed useful genetic diversity and the visual displays appeared to disperse the lines somewhat more evenly over the plot than the morphological and physiological methods.
\end{abstract}

Key words: DUS; Inbred Lines; Maize; Markers; Genetic Distance; Diversity

\section{INTRODUCTION}

Maize is grown world wide on an approximately 161 million ha annually with a production of 685 million metric tonnes [1]. It occupies an important position in the world economy and trade as a food, feed and an industrial grain crop. Several million people in the developing world consume maize as a staple food and derive their protein and calories requirement form it. Development of high yielding hybrids is the most important objective of any maize breeder to enhance productivity. For developing hybrids, better inbred lines with high mean performance are required.

DUS Testing is one of the important criteria to test inbred lines for distinctness, uniformity and stability. DUS Testing of cultivars is one of the requirements for granting Plant Breeders Rights (PBR) and it is conducted according to national guidelines prepared on the basis of UPOV guidelines. The system accepted and in operation in a large number of countries is as provided by UPOV. Information is, thus, generated on the basis of internationally accepted and followed norms, thereby providing a basis for appropriate comparison of materials identified under the national agricultural research system (NARS) along side materials from other sources.

Maize inbred lines represent a fundamental resource for studies in genetics and breeding and are used extensively in hybrid corn production [2,3]. Inbreds have also been critical for molecular evaluation [4,5]. Knowledge of genetic diversity in maize germplasm helps to ensure that a broad genetic base of breeding materials is maintained, not just for sustaining genetic improvement but also for reducing genetic vulnerability to pests and diseases. This information may be obtained from pedigree and test cross data, morphological and biochemical traits or molecular markers and it is important for maximizing heterosis because molecular markers can characterize lines directly and precisely at the DNA level. They can help maize breeders in efficiently assigning lines to heterotic groups and guide them in the choice of parents for the development of new hybrids. Several types of mo- 
lecular markers are available for evaluating the extent of genetic diversity in maize. These include (RFLP, RAPD, AFLP, SSR, etc). The assessment of genetic diversity within and among populations has been the concern of several researchers in the past and it is especially important for plant genetic resource management [6,7].

The objective of this study was to determine the potential utility of morphological, physiological and RAPD markers for application in research, product development, seed production, intellectual property right (IPR), and genetic resource conservation management in maize. To accomplish this goal, we report molecular profile and pedigree data for a set of 30 inbred lines. We assessed the discrimination ability of data obtained from morphology, physiology and RAPD; and compared inbred lines that are revealed by these data with association that would be expected on the basis of known pedigrees. We also discuss the cost of effectiveness of acquiring RAPD data with respect to the potential use of this technology by breeders and conservators.

\section{MATERIALS AND METHODS}

Morpho-agronomic studies and RAPD characterization of maize inbred lines on UPOV harmonized characteristics, generally as per DUS test guideline $[8,9]$ were undertaken.

1) Seed material used and test conditions

The experimental material used for the present study comprised 30 maize inbreeds (data not shown) developed under the auspices of GBPUA\&T, Pantnagar and used in hybrid breeding programme, were grown at the Crop Research Centre, G. B. Pant University of Agriculture and Technology, Pantnagar. Two evaluation trials were conducted during Kharif, 2002 and Kharif, 2003. In addition, these lines were selfed and selfed seed was harvested separately, for molecular analysis. Recommended package of agronomic practices and plant protection measures were adopted.

2) Characteristics used for morphological and physiological evaluation

UPOV's DUS test guidelines [10,11] were generally followed beginning from the trial layout to recording of the last field related observation. In UPOV [11] 34 morphological and physiological characteristics to be recorded in maize at different stages of plant growth are given. Out of these, 12 characteristics are marked with asterisk $(*)$, which means that characteristics have to be compulsorily observed in every environment. Keeping this in view, a total number of 27 characteristics were selected for observations. Characters considered for testing of inbred lines [12] are given in Table 1.

3) Molecular characterization
The same set of 30 inbred lines used in the morphological \& physiological study, were used for molecular characterization by RAPD analysis. Leaves from 6-8 plants (3-4 leaf stage) were bulked and ground to a fine powder with liquid nitrogen using a mortar and pestle. DNA was extracted using a modified CTAB procedure [13]. Chemicals, glasswares and instruments used for this study were as per standardized source.

\subsection{Amplification and Detection Conditions}

Approximately $10 \mathrm{ng}$ of DNA was used as template for PCR in $25 \mu \mathrm{l}$ reaction containing $1 \mathrm{X}$ PCR buffer, 200 $\mu \mathrm{M}$ each dNTPs, $0.76 \mathrm{U}$ Tag polymerase and $30 \mathrm{ng}$ of primer (PCR buffer, dNTPmix, Taq polymerase and primers were from Bangalore Genei Pvt. Ltd.). The details of lot number and sequence of primers are given in Table 2. Amplification was carried out using eppendorf thermocycler by the following amplification conditions i.e., initial denaturation at $94^{\circ} \mathrm{C}(5 \mathrm{~min}$.); 36 cycles of $94^{\circ} \mathrm{C}$ (30 sec.) denaturation, $34^{\circ} \mathrm{C}$ (1 min) annealing, and $72^{\circ} \mathrm{C}(1 \mathrm{~min})$ extension; and then a final extension at $72^{\circ} \mathrm{C}$ (5 min). $2 \%$ Agarose gel was prepared for fractionation of RAPD markers. During preparation of Agarose gel $5 \mu \mathrm{l}$ Ethidium bromide stack $(10 \mathrm{mg} / \mathrm{ml})$ was added. DNA template and dye were loaded in 5:1 ratio and electrophoresis was done at $60 \mathrm{~V}$ for $4-5 \mathrm{hrs}$ in $1 \mathrm{X}$ TBE buffer.

\subsection{Gel Scoring}

The amplification products were scored separately for each primer. The bands observed on the gel were compared across the lanes for products with similar molecular weight, based on specific molecular weight marker. The bands were scored for the presence or absence by binary coding, i.e., assigning a value of 1 for presence and 0 for absence in a lane.

\subsection{Data Analysis}

To determine the relationships among lines, we calculated similarities (dissimilarities) between inbred lines from different data sets as follows:

1) Pair-wise comparisons for understanding 'clear distinguishability' among inbreds:

The single values obtained for each characteristic for each plant were compared with each other inbred over the set of seven characteristics. A characteristic was considered to be clearly distinct between the pair of inbreds under comparison, if there was no overlapping of the description and there was a clear difference of at least 
Table 1. Characters used in DUS testing of inbred lines.

\begin{tabular}{|c|c|c|c|c|}
\hline Sl. No. & Characters and code & Stage of observation & Expression & Score \\
\hline \multicolumn{5}{|c|}{ A. Physiological characteristics } \\
\hline \multirow{3}{*}{1.} & & & Poor & 1 \\
\hline & Early plant vigour PLT_VGR & To be recorded after 25 days of sowing & Good & 2 \\
\hline & & & Very good & 3 \\
\hline \multirow{3}{*}{2.} & & & Lax & 3 \\
\hline & Tassel texture, TAS_TXT & To be recorded after tasselling & Medium & 5 \\
\hline & & & Dense & 7 \\
\hline \multirow{4}{*}{3.} & \multirow{4}{*}{ Tassel anther glume colour, ANT_GCLR } & \multirow{4}{*}{-do- } & Pink & 1 \\
\hline & & & Green & 2 \\
\hline & & & Light purple & 3 \\
\hline & & & Purple & 4 \\
\hline \multirow{2}{*}{4.} & \multirow{2}{*}{ Tassel-glume base colour, GLUM_CLR } & \multirow{2}{*}{-do- } & Absent & 0 \\
\hline & & & Present & 1 \\
\hline \multirow{4}{*}{5.} & \multirow{4}{*}{ Silk colour at emergence, SILK_CLR } & \multirow{4}{*}{ To be recorded 5-6 days after silking } & Green & 1 \\
\hline & & & Pink & 2 \\
\hline & & & Red & 3 \\
\hline & & & Purple & 4 \\
\hline \multirow{4}{*}{6.} & \multirow{4}{*}{ Leaf colour, LF_CLR } & \multirow{4}{*}{ To be recorded at full-foliage stage } & Yellowish green & 1 \\
\hline & & & Light green & 2 \\
\hline & & & Green & 3 \\
\hline & & & Dark green & 4 \\
\hline \multirow{2}{*}{7.} & \multirow{2}{*}{ Leaf orientation, LF_ORI } & \multirow{2}{*}{-do- } & Erect & 1 \\
\hline & & & Drooping & 2 \\
\hline \multirow{3}{*}{8.} & \multirow[b]{2}{*}{ Leaf pubescence, LF_PUB } & \multirow[b]{2}{*}{-do- } & Absent & 0 \\
\hline & & & Present & 1 \\
\hline & & & Smooth & 1 \\
\hline \multirow[t]{2}{*}{9.} & Leaf texture, LF_TEXT & -do- & Leathery & 2 \\
\hline & & & Normal & 3 \\
\hline \multirow{3}{*}{10.} & \multirow{2}{*}{ Anthocyanin pigmentation, ANTH_PIG } & \multirow[b]{2}{*}{-do- } & Absent & 0 \\
\hline & & & Present & 1 \\
\hline & & & Poor & 3 \\
\hline \multirow[t]{2}{*}{11.} & Husk cover, HUSK_CVR & $\begin{array}{c}\text { To be recorded using ears on five random } \\
\text { plants }\end{array}$ & Intermediate & 5 \\
\hline & & & Good & 7 \\
\hline \multirow[t]{2}{*}{12.} & Ear shape, EAR_SHP & To be recorded after harvesting & Cylindrical & 1 \\
\hline & & & Cylindrical-Conical & 2 \\
\hline
\end{tabular}




\begin{tabular}{|c|c|c|c|c|}
\hline & & & Conical & 3 \\
\hline & & & Round & 4 \\
\hline & & & Regular & 1 \\
\hline \multirow{3}{*}{13.} & & & Irregular & 2 \\
\hline & Kernel row arrangement, KER_ARR & -do- & Straight & 3 \\
\hline & & & Spiral & 4 \\
\hline \multirow[t]{4}{*}{14.} & Kernel colour, KER_CLR & -do- & White & 1 \\
\hline & & & Yellow & 2 \\
\hline & & & Variegated & 3 \\
\hline & & & Orange & 4 \\
\hline \multirow[t]{4}{*}{15.} & Grain shape, GRN_SHP & -do- & Shrunken & 1 \\
\hline & & & Round & 2 \\
\hline & & & Indented & 3 \\
\hline & & & Pointed & 4 \\
\hline \multirow[t]{3}{*}{16.} & Grain size, GRN_SIZ & -do- & Small & 3 \\
\hline & & & Medium & 5 \\
\hline & & & Bold & 7 \\
\hline
\end{tabular}

\section{B. Morphological/Quantitative characters}

\section{Days to tasseling, DAY_TASS}

18. Days to silking, DAS_SILK

19. Tassel branching, TASS BRN

20. Plant height $(\mathrm{cm})$, PLT_HGT

21. Ear height (cm), EAR_HGT

22. Ear length (cm), EAR_LT

23. Ear width (cm), EAR_WD

24. Number of kernel rows, KER_ROW

25. Number of kernels/row, KER PROW

26. 100 seed weight (g), SED_WGT

27. Grain yield / plant (g), YLD_PLT
To be recorded as number of days from sowing to when $50 \%$ of the plants have shed pollen. Pollen shading on the central axis is recorded as tassel emergence Number of days from sowing to when silks have emerged on $50 \%$ of the plants. Silk emergence in plants is recorded as days to silk

To be recorded after tasseling

To be measured from ground level to the base of the tassel (after milk stage)

To be measured from base of the plant to the point bearing the first ear

To be measured as distance from the base of the tip of the ear

To be measured at the central part of the upper most ear as maximum girth of the ear

To be recorded as number of kernel - rows in the central part of the uppermost ear

To be recorded as average number of kernels/five - rows of five respective ears

To be recorded after harvesting

Average yield of five random plants are scored 
Table 2. Primer codes and sequence.

\begin{tabular}{ccl}
\hline S. No. & Primer code & Sequence \\
\hline 1. & OPP-01 & GTAGCACTCC \\
2. & OPP-02 & TCGGCACGCA \\
3. & OPP-04 & GTGTCTCAGG \\
4. & OPP-07 & GTCCATGCCA \\
5. & OPP-08 & ACATCGCCCA \\
6. & OPP-14 & CCAGCCGAAC \\
7. & OPP-15 & GGAAGCCAAC \\
8. & OPP-16 & CCAAGCTGCC \\
9. & OPE-14 & TGCGGCTGAG \\
10. & OPC-15 & GACGGATCAG \\
\hline
\end{tabular}

one character-state, another criterion for clear distinguishability in UPOV guidelines [10].

2) Morphological and physiological comparison of inbred lines:

The mean values for eleven morphological characters and scaling values for physiological characters were used to assess dissimilarity between inbred lines. The matrix of all the characteristics was standardized and used to calculate euclidean distances among the inbreds. A dendrogram was constructed using Sequential Aggolomerative Hierarchical and Nested clustering Analysis (SAHN) to provide a general visualization of relationship between inbreds on morphological and physicogical characteristics.

3) RAPD analysis to establish distinctness:

From the presence/absence of bands, matrix of data on the basis of their $\mathrm{Rm}$ values, similarity coefficients among the inbreds were calculated following [14]. As shown in (1).

PCR amplification data from the samples that were inconsistent were not included in the final statistical analysis. The similarity matrix was also subjected to SAHN clustering analysis to construct dendrogram.

All the numerical taxonomic analyses with respect to morpho-agronomic and RAPD were performed using the SAS software, and NTSYS-pc software [15].

\section{RESULTS}

\subsection{Pair-Wise Comparison for Understanding 'Clear Distinguishability' among Inbreds}

Data on each plant from different inbred lines were subjected to measure clear distinguishability by a difference of at least one character-state in different pos- sible pairs of 30 inbreds. Table 3 shows number of inbred pairs in which different characteristics appeared to contribute towards 'clear distinguishability' provid- ing the final ranking of different characteristics for discrimination among different inbreds. There was a wide range of distinguishability across the inbred lines. Tassel branching, which is the key characteristic for use of different inbreds as male parents in hybrid production occupied first position. Other characteristics, such as plant height, kernels/row, ear height, ear length and ear width for which good degree of uniformity has been maintained also occupied good position in 'clear distinguishability'.

\subsection{Morphological Characters}

The mean values for 11 morphological characters were subjected to dissimilarity analysis. The dissimilarity matrix Table 4 and on the basis of matrix dendrogram was constructed Figure 1 to provide general visualization. Given this diversity, all 30 lines were found to differ

Table 3. Importance of different characteristics in terms of their contribution towards 'clear distinguishbility'.

\begin{tabular}{cccc}
\hline $\begin{array}{c}\text { SL. } \\
\text { NO. }\end{array}$ & Characteristics & $\begin{array}{c}\text { Number of pairs } \\
\text { separated }\end{array}$ & rank \\
\hline 1. & TASS_BRN & 396 & 1 \\
2. & PLT_HGT & 384 & 2 \\
3. & EAR_HGT & 367 & 4 \\
4. & EAR_LT & 364 & 5 \\
5. & EAR_WD & 333 & 6 \\
6. & KER_ROW & 311 & 7 \\
7. & KER_PROW & 383 & 3 \\
\hline
\end{tabular}


Similarity Index $=\frac{\text { No. of matching bands in two lanes compared }}{\text { Total number of bands }}$

from each other industrial. The genetic distance between inbred 2 and inbred 12 was the least (1.6). The maximum genetic distance was noted between inbred 17 and 25 followed by inbred 10 and 17; and 15 and 17. Dendrogram resulting from cluster analysis of 30 inbred lines could be primarily divided into three major groups.

\subsection{Physiological Characters}

For physiological characters different scaling values were used to assess dissimilarity between inbred lines. The results obtained by this analysis is presented in Table 5 (dissimilarity matrix) and Figure 2. (dendrogram) respectively. Genetic distance varied from 0.35 to 1.92 for 30 inbred lines. The minimum distance indicating closely related inbred lines was between inbred 13 and 23 (0.35). Two inbred lines that highly differed from each other were 2 and 20 (1.92). Dendrogram made on the basis of dissimilarity matrix showed five main clusters, and within these clusters different number of lines were present.

\subsection{Feasibility to Establish Distinctness Using Rapd}

The bands generated from the 10 primer combinations across 30 inbred lines were used to work out genetic distance. Random primers provide highly polymorphic amplification product. The distance varied from 0.42 to 0.65 Table 6. Between inbred lines 27 and 29 it was the least $(0.42)$. The farthest genetic distance was found between inbred lines 2 and 20; 2 and 28; and 3 and 16 . In general, inbred 2 was genetically more distinct and diverse from other lines under study.

The dendrogram of 30 lines is shown in Figure 3. These lines formed closed clusters due to reduced amount of variation between them. Lines did not cluster according to source population, which has been reported in other studies also showing large amount of diversity within the source populations relative to between populations [16]

\subsection{Discussion}

The question of Plant Variety Protection (PVP) has been brought into worldwide focus by the agreement on Trade Related Aspects of Intellectual Property Right (TRIPS), which is a part of GATT (General Agreement on Tariffs and Trade) Agreement establishing the World
Trade Organization (WTO) in 1995. The PBR concept is based on the realization that if commercial plant breeding is to be encouraged for the benefit of agriculture and society, measures have to be taken to allow breeders to profit from their product [17]. Further, it makes possible to define a plant grouping with sufficient specificity to allow the unambiguous assignment and enforcement of property rights.

Analysis of genetic diversity and of relationship among the elite breeding materials can significantly aid in crop improvement [18]. In maize, this information is useful in planning for hybrid and line development, assigning lines to heterotic groups and in plant variety protection [19], molecular markers are more powerful in assessing genetic diversity in comparison with the morphological data, pedigree data and biochemical data, because these markers reveal differences at the level of DNA [20]. The lines used in this study were a small but representative sample of existing commercial hybrids, and so typified the kind of diversity encountered by the testing authorities conducting registration tests. They were all morphologically and physiologically distinct, as would be expected.

In the present study, the molecular markers also exposed useful genetic diversity, and the visual displays appeared to disperse the line somewhat more evenly over the plot than the morphological and physiological method. However, there was little agreement on variety relationships between the morphology, physiology and the molecular methods. Other workers have reported a distances [21-24]. Lines that display high phenotypic dissimilarity need not be genetically dissimilar. The purpose of pre-screening would be to subdivide candidate varieties into groups, so reducing the number of controls and pair-wise comparisons that have to be examined in the morphology test. However, this process assumes that the pre-screening characters guarantee that varieties placed in different groups are distinct in the morphological characters used for registration. Clearly, this would not be the case as the present study showed that molecular and morphological differences were not correlated. Therefore, using molecular markers as groupingcharacters would by default, require acceptance of their use as a distinguishing characters, at least for the mostdivergent inbred lines. An alternative way to deal with the poor correlation between genetic and morphological distances could be to select only molecular markers 


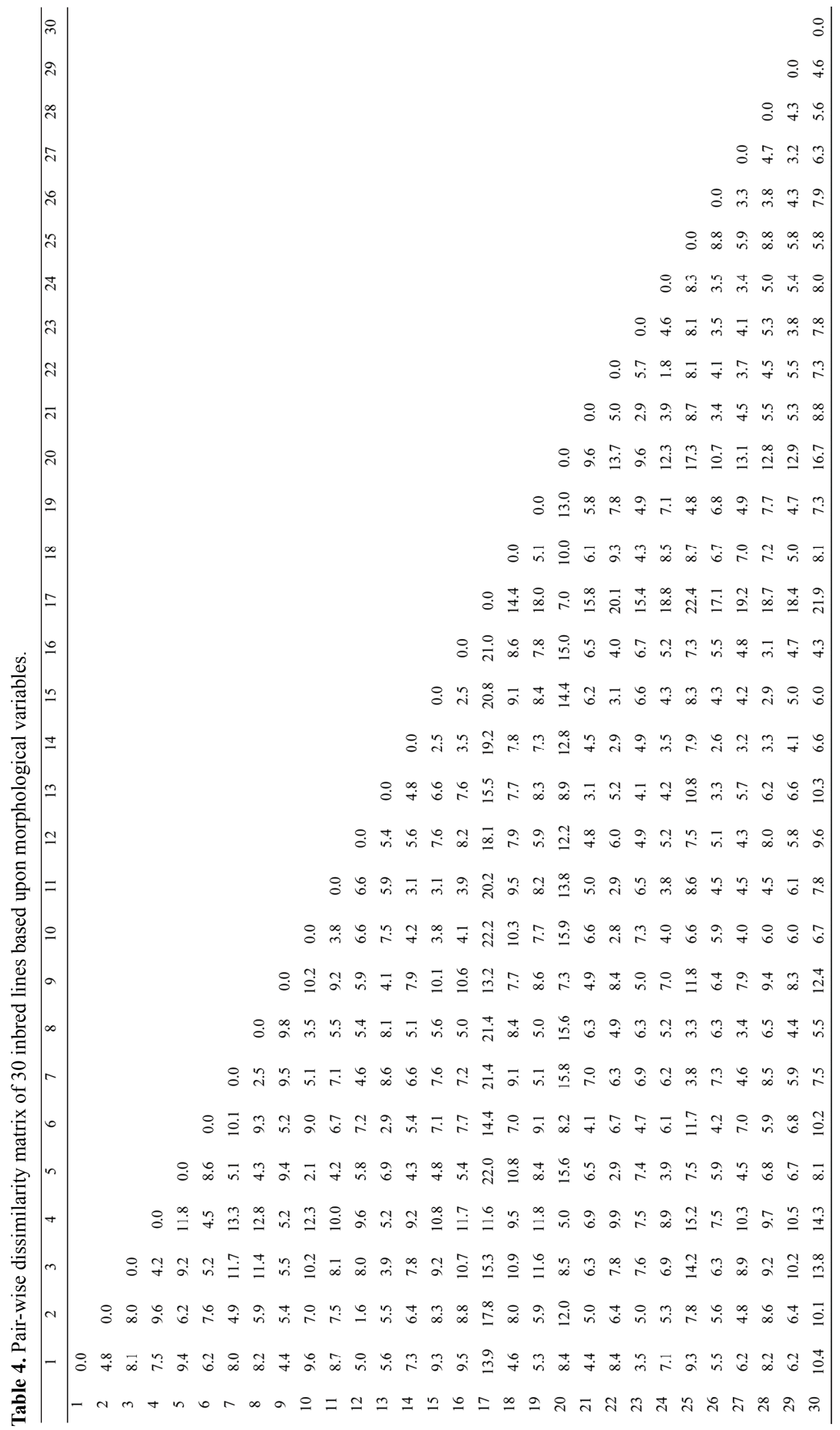




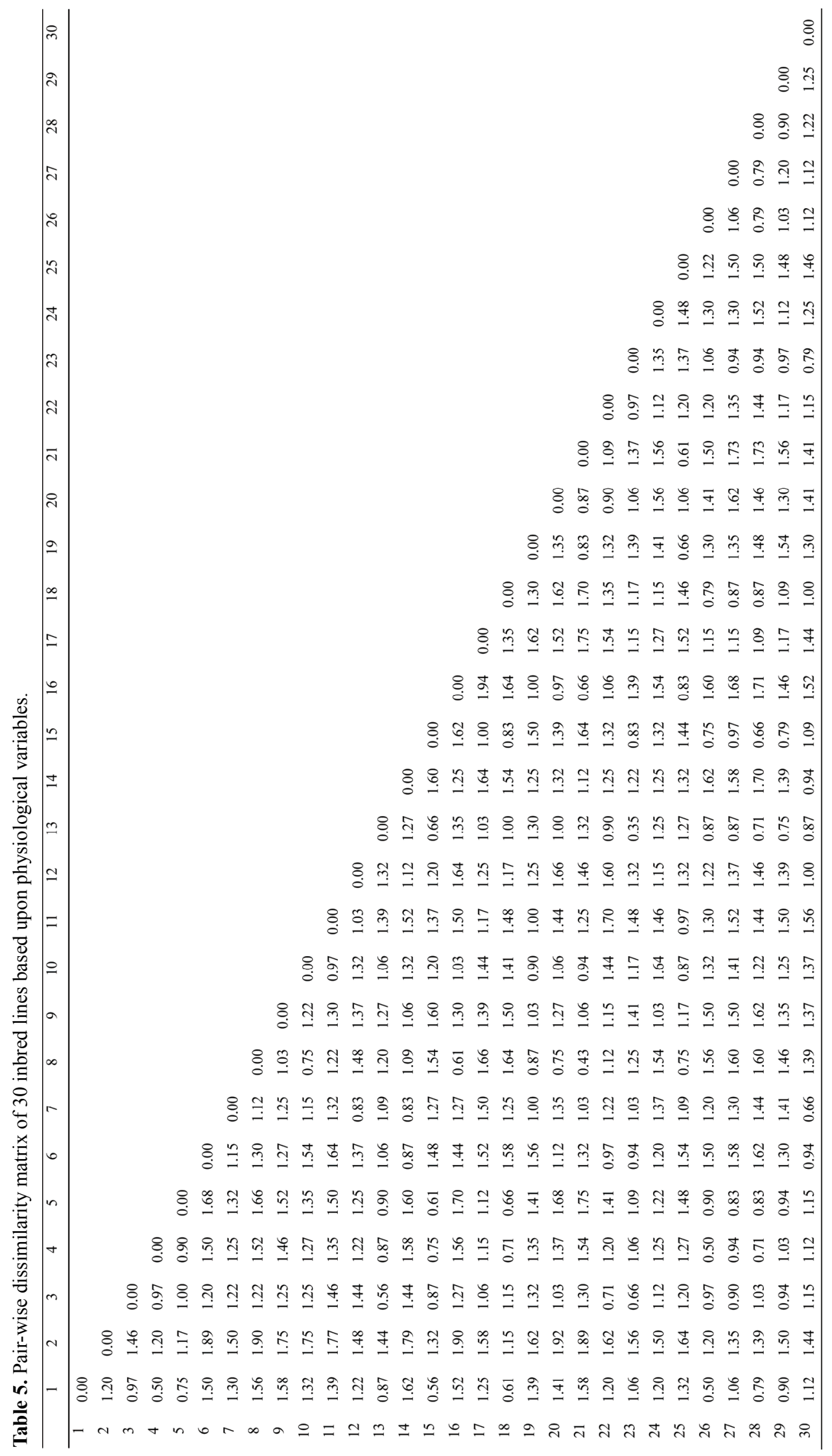




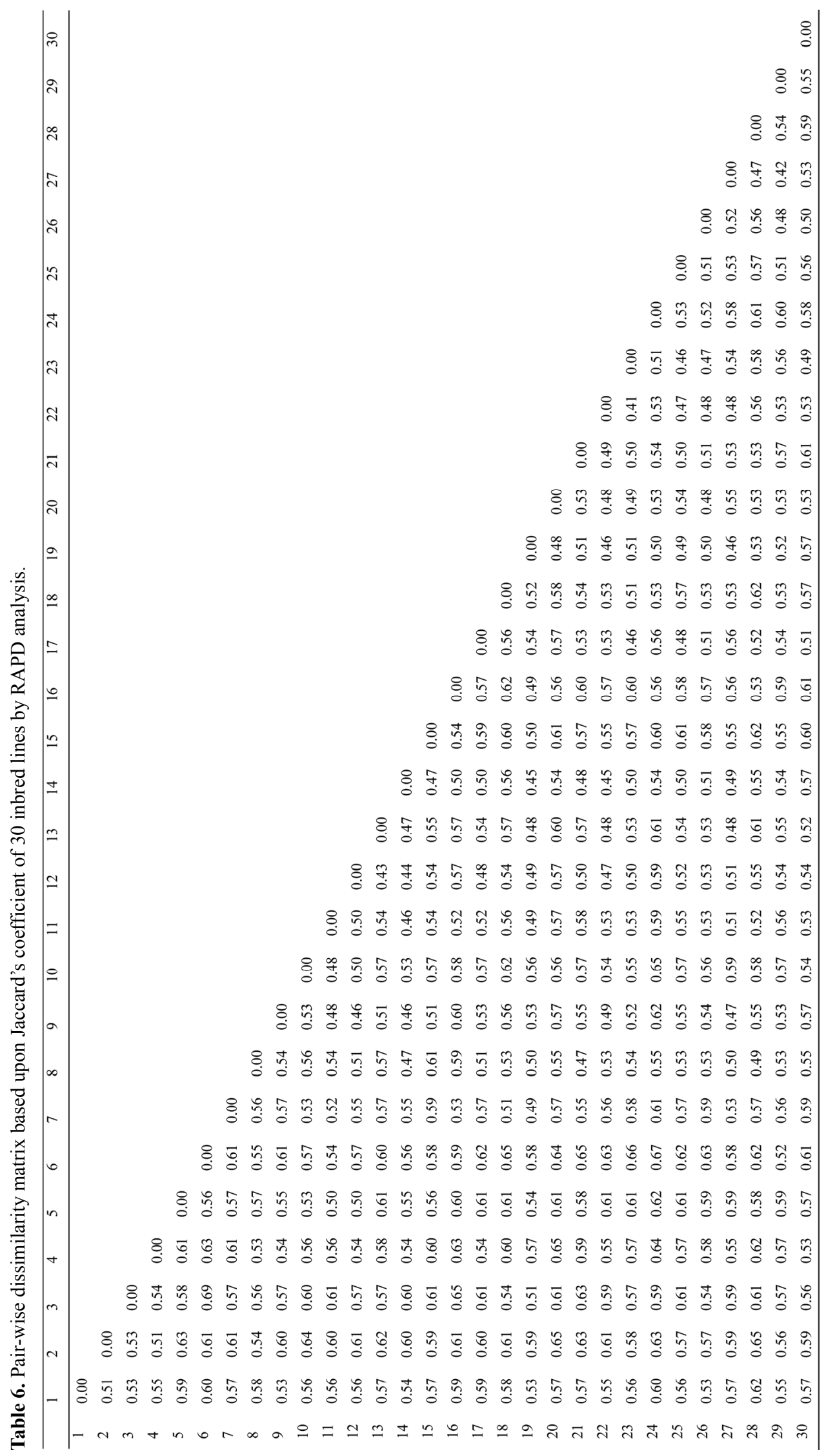




\section{Dendrogram of 30 inbred lines based upon mean of 11 morphological variables}

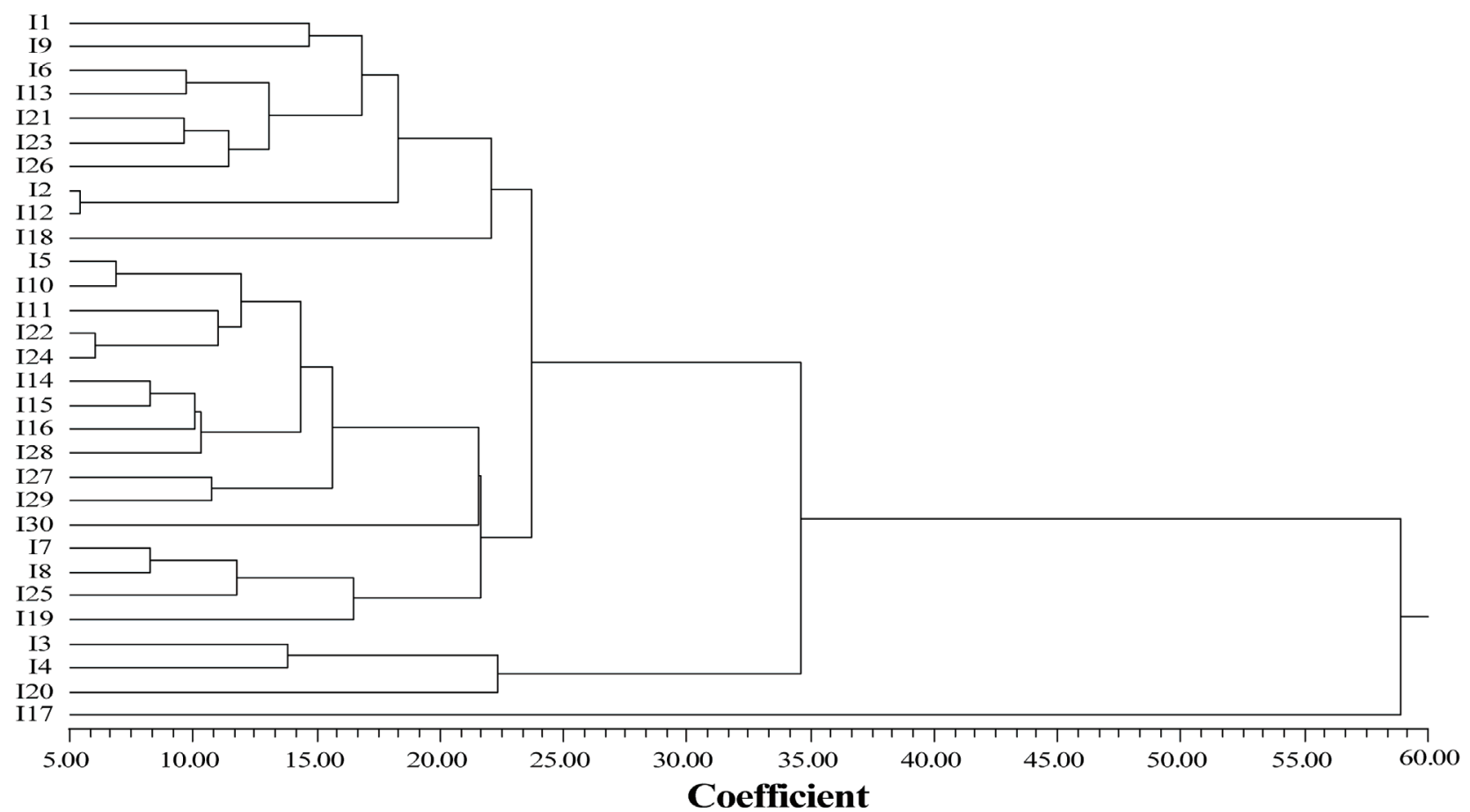

Figure 1. Dendrogram of 30 inbred lines based upon mean of 11 morphological variables.

\section{Dendrogram of 30 inbred lines based upon mean of 16 morphological variables}

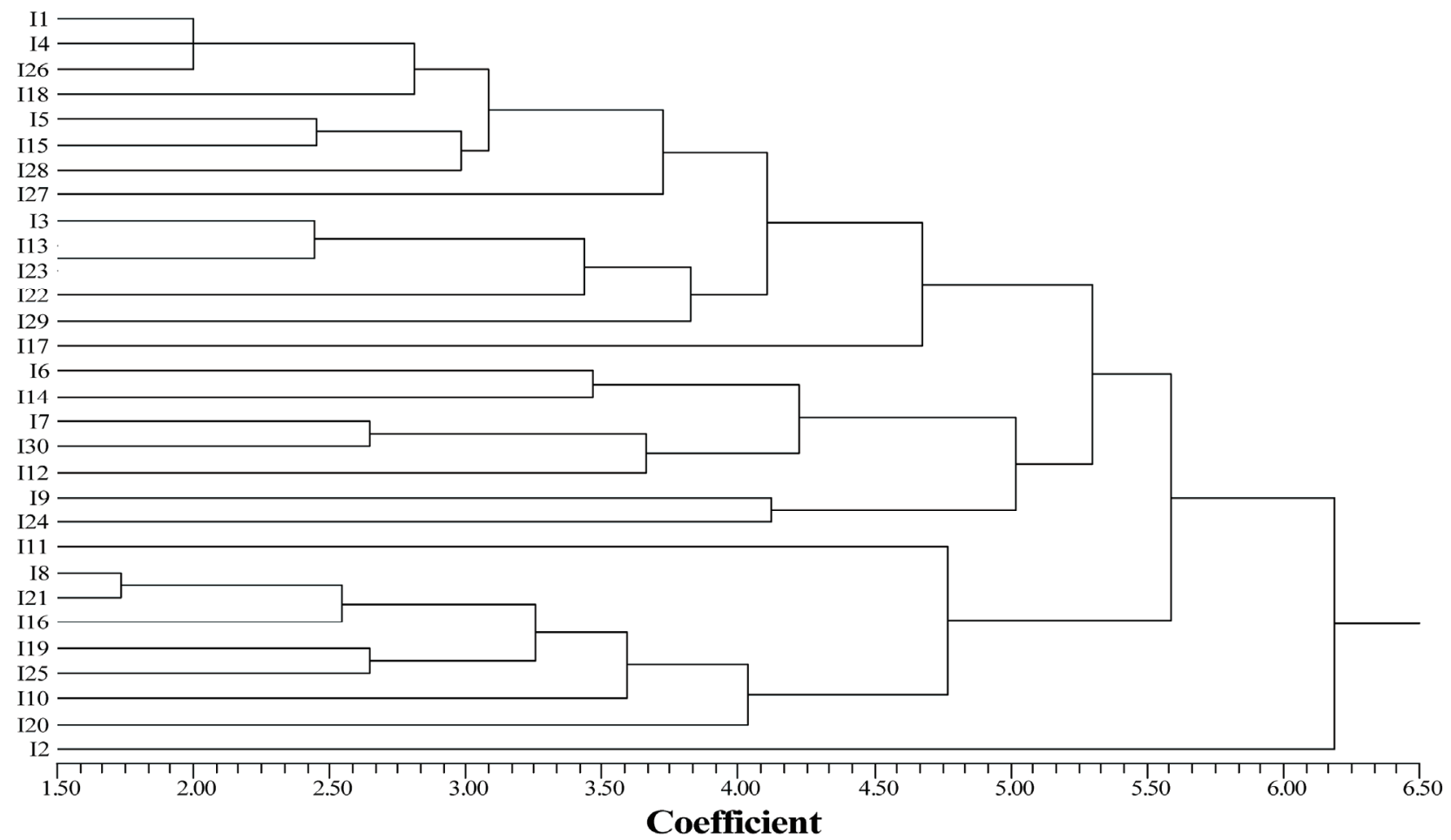

Figure 2. Dendrogram of 30 inbred lines based upon mean of 16 physiological variables. 
Dendrogram of 30 inbred lines based upon RAPD analysis

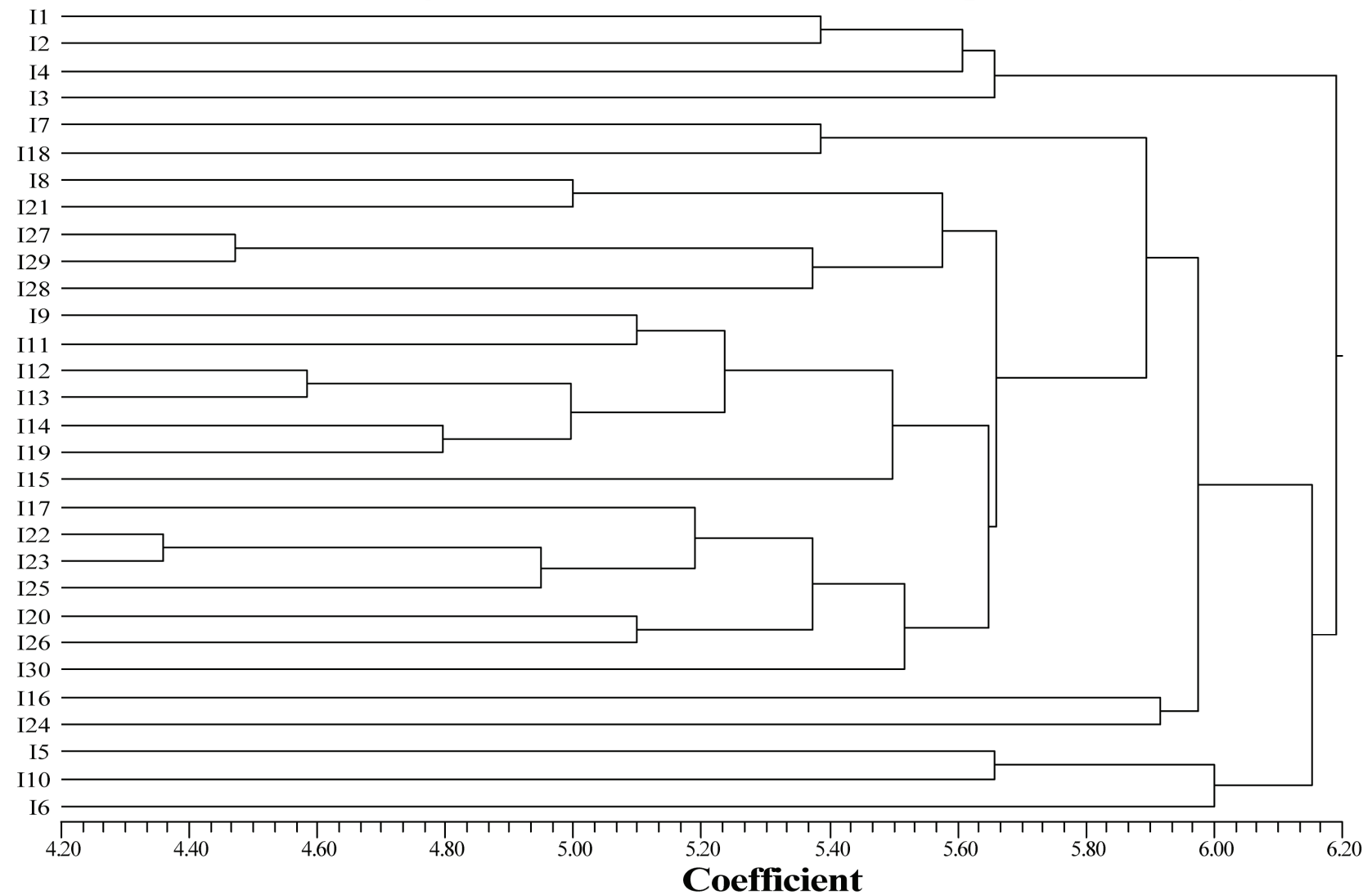

Figure 3. Dendrogram of 30 inbred lines based upon RAPD analysis.

linked to phenotypic traits in DUS testing.

The diversity patterns of the inbred lines revealed a large amount of diversity that did not allow a clear-cut distinction between groups. This case is similar to that of the CIMMYT populations, which served as germplasm sources for many of the Asian lines [16], where a large amount a diversity within, relative to between, source populations was observed. On the other hand, the heterotic groups in the US and European temperate maize were clearly differentiated in previous studies using RFLPs and SSRs [23-27].

This study is an initial attempt to characterize the breadth of germplasm diversity, from which we concluded that breeding activity at Pantnagar has not caused a decline in the overall amount of diversity in the inbred lines. In sum and substance, it can be stated that although the work had concentrated on DUS testing, it is myth and less a reality. There are only small number of descriptors available in released and notified cultivars in India and their parental lines. If an attempt is made by considering a large number of descriptors, establishment of 'clear distinguishability for each material may not be difficult. Morphological markers and molecular markers with insufficient primers do not generate sufficient diversity in the population. So sufficient primers which cover whole genome should be used in the further studies on DUS testing.

\section{REFERENCES}

[1] (2008) FAOSTAT, Food and Agricultural Organization, Rome.

[2] Anderson, E. and Brown, W.L. (1952) Origin of corn belt maize and its genetic significance, In: Heterosis - A Record of Researches Directed toward Explaining and Utilizing the Vigor of Hybrids, Gowen, J.W., Ed., Iowa State College Press, Ames, 124-148.

[3] Troyer, A.F. (2001) Temperate corn. In: Hallauer, A., Ed., Specially Corns, CRC Press, Boca Raton.

[4] Henry, A. and Damerval, C. (1997) High rates of ploymorphism and recombination at the Opaque-2 locus in cultivated maize. Molecular and General Genetics, 256, 147-157.

[5] Ching, A., Caldwell, K.S., Jung, M., Dolan, M. and Smith, O.S. (2002) SNP frequency, haplotype structure and linkage disequilibrium in elite maize inbred lines. BMC Genet, 3(19), 1-14.

[6] Bretting, P.K. and Widrlechner, M.P. (1995) Genetic markers and plant genetic resource management. Plant 
Breeding Reviews, 13, 11-86.

[7] Hamrick, J.L. and Godt, M.J.W. (1989) Allozyme diversity in plant species. In: Brown, A.H.D., Clegg, M.T., Kahler, A.L. and Weir, B.S., Eds., Plant Population Genetics, Breeding, and Genetic Resources, Sinouer Association, Sunderland, 43-63.

[8] UPOV (1979) Revised general introduction to the guidelines for the conduct of tests for distinctness, homogeneity and stability of new varieties of plants. UPOV TG/1/2, 11.

[9] UPOV (1980) Guidelines for the conduct of tests for distinctness, homogeneity and stability - maize (Zea mays L.). UPOV TG/2/4, 14.

[10] UPOV (1991) UPOV Publication No. 221(E) of 1992 on international convention for the protection of new varieties of plants of December 23, 1978; and on March 19, 1991. 31.

[11] UPOV (1994a) Guidelines for the conduct of tests for distinctness, homogeneity and stability-maize (Zea mays L.). UPOV TG/2/6, 63 .

[12] Sujay, R. and Singh, N.N. (2001) Guidelines for conduct of test for distinctness, uniformity and stability in maize (Zea mays L.). Directorate of maize Research, New Delhi.

[13] (2001) The applied biotechnology center's manual of laboratory protocols. CIMMYT, Mexico.

[14] Jaccard, P. (1908) Nouvelles researches sur la distribution florale. Bulletin de la Société vaudoise des sciences naturelles, 44, 223-270.

[15] Rohlf, F.J. (1992) NTSYS-pc Numerical taxonomy and multivariate analysis system. Exeter Software, New York.

[16] Warburton, M.L., Xianchun, X., Crossa, J., Franco, J., Melchinger, A.E., Frisch, M., Bohn, B. and Hoistington, D. (2002) Genetic characterization of CIMMYT inbred maize lines and open pollinated populations using large scale fingerprinting methods. Crop Science, 42, 18321840 .

[17] Mishra, J.P. (1999) Biotechnology and intellectual property rights. Yojana, May, 15-20.

[18] Hallauer, A.R., Russel, W.A. and Lamkey, K.R. (1988) Corn breeding. In: Sprague, G.F. and Dudley, J.W., Eds., Corn and Corn Improvement, 3rd Edition, Agronomy
Monograph, 18, ASA, CSSA and SSSA, Madison, 463564.

[19] Yuan, L., Zhang, S., Warburton, M., Li, X., Fu, J. and Li, M. (2002) Assessment of genetic similarities among maize inbred lines using SSR markers. In: Proceedings of the Eighth Asian Regional Maize Workshop, Bangkok, 50-58.

[20] Melchinger, A.E. (1999) Genetic diversity and heterosis. In: Coors, J.G. and Pandey, S., Eds., Proceedings of the International Symposium on Genetics and Exploitation of Heterosis in Crops, CIMMYT, Mexico, 17-22 August 1997, 3-48.

[21] Ben-Har, A., Charcoset, A., Bourgoin, M. and Guiard, J. (1995) Relationships between genetic markers and morphological traits in a maize inbred lines collection. Euphytica, 84, 145-154.

[22] Burstin, J. and Charcosset, A. (1997) Relationship between phenotypic and markers distance: Theoretical and experimental investigations. Heredity, 78, 477-483.

[23] Senior, M.L., Murphy, J.P., Goodman, M.M. and Stuber, C.W. (1998) Utility of SSRs for determining genetic similarities and relationship in maize using and Aqarose gel system. Crop Science, 38, 1088-1098.

[24] Smith, J.S.C., Chin, E.C.L., Shu, H., Smith, O.S., Wall, S. J., Senior, M.L., Mitchell, S.E. Kresobitch, S. and Ziegle, J. (1997) An evaluation of the utility of SSR loci as molecular markers in maize (Zea mays L): Comparisons with data from RFLPs and Pedigree. Theoretical and Applied Genetics, 95, 163-173.

[25] Messmer, M.M., Melchinger, A.E. and Boppenmaier, E. (1992) Relationship among European maize inbreds: I. Genetic diversity among flint and dent lines revealed by RFLPs. Crop Science, 32, 1301-1309.

[26] Messmer, M.M., Melchinger, A.E., Boppenmaier, J., Brunklaus-Jung, E. and Herrmann, R.G. (1992) Relationship among early European maize inbreds: I. Genetic diversity among flint and dent lines revealed by RFLPs. Crop Science, 32, 1301-1309.

[27] Dubreuil, P., Dufour, P., Drejci, E., Causse, M.M., de Vienne, D. Gallais, A. and Char Cosset, A. (1996) Organization of RFLP diversity among inbred lines of maize representing the most significant heterotic groups. Crop Science, 36, 790-799. 